\title{
SUSCEPTIBILIDADE DE AMBIENTES CAMPESTRES À INVASÃO DE ACÁCIA-NEGRA (Acacia mearnsii De Wild.) NO RIO GRANDE DO SUL
}

\author{
Silas Mochiutti*, Antonio Rioyei Higa**, Augusto Arlindo Simon*** \\ *Eng. Agrônomo, M.Sc., Doutorando em Eng. Florestal, UFPR, Embrapa Amapá - silasmochiutti@terra.com.br \\ **Eng. Florestal, Ph.D., Depto. de Ciências Florestais, UFPR - higa@ufpr.br \\ ***Eng. Florestal, TANAGRO - aasimon@tanac.com.br \\ Recebido para publicação: 20/02/2006 - Aceito para publicação: 10/10/2006
}

\begin{abstract}
Resumo
O objetivo deste trabalho foi avaliar a freqüência, a intensidade e o padrão de invasão da acácia-negra em ambientes campestres e propor medidas de monitoramento e controle. Foram avaliados sete ambientes localizados em áreas a menos de $30 \mathrm{~m}$ de povoamentos jovens ( 1 ano) e adultos (5 anos). A invasão da acácia-negra esteve relacionada ao grau de perturbação do solo. A Área de Preservação Permanente (APP) em recuperação, o ambiente mais perturbado, apresentou também o maior número de invasoras, sendo encontradas 152 plantas $/ 0,1$ ha. Em ambientes pouco perturbados, como o banhado, campo nativo e APP sem uso recente, verificou-se menos de 11 plantas $/ 0,1$ ha. Foi verificado um maior número de invasoras nas áreas mais próximas de povoamentos jovens $(50$ plantas $/ 0,1 \mathrm{ha}$ ) que de plantios adultos (10 plantas/ $0,1 \mathrm{ha})$, indicando que perturbações que resultaram em invasão foram as causadas principalmente por máquinas durante a colheita e estabelecimento da nova rotação. A ocorrência de novas invasões durante o ciclo de crescimento do cultivo foi insignificante $(<1$ plantas $/ 0,1$ ha). A mortalidade no período de um ano foi de 80,4, 14,0, 6,8 e 5,5\%, respectivamente, para plantas $<0,5,0,5$ a $1,9,2,0$ a 4,0 e $>4,0$ m de altura, reduzindo significativamente a população de invasoras nos anos seguintes à invasão. A invasão da acácia-negra está condicionada a perturbações no solo, por isso deve ser considerada uma invasora causal de ambientes campestres.

Palavras-chave: Invasora causal; perturbações de solos; estepe; campos sulinos.
\end{abstract}

\begin{abstract}
Grassland ecosystem susceptibility for invasive of the black wattle (Acacia mearnsii De Wild.) in the Rio Grande do Sul State, Brazil. This paper aimed to evaluate the frequency, the intensity and the pattern of black wattle invasion on field environment, and to propose methodologies for its monitoring and control. Seven environments located less than $30 \mathrm{~m}$ from young ( 1 year) and mature (5 years) plantations were evaluated. Black wattle invasions depended on the degree of soil disturbance. A Permanent Preservation Area (APP) in a recuperation phase, the most disturbed environment studied, presented 152 plants $/ 0.1$ ha, the highest number of invasive plants observed. Less than 11 plants/ha were observed on environments with low disturbance rates, such as native grassland, swamp areas and undisturbed APP's. Environments near young black wattle plantations were more susceptible to invasions (50 plants $/ 0.1 \mathrm{ha}$ ) than environments near mature plantations ( 10 plants/ 0.1 ha), suggesting that the disturbance was caused by machineries used in harvesting and reforestation operations. New invasions during the following growth cycle were not significant $(<1 \mathrm{plant} / \mathrm{ha})$. Mortality in a one year period was of $80.4 ; 14.0 ; 6.8$ and $5.5 \%$, for plants $<0.5 \mathrm{~m} ; 0.5 \mathrm{~m}$ to $1.9 \mathrm{~m} ; 2.0 \mathrm{~m}$ to $4.0 \mathrm{~m}$ and $>4.0$ of height, respectively, showing that the populations of invasive plants were significantly reduced during the following years. Thus, black wattle invasion to neighbouring plantations was conditioned to soil disturbance rates, and as such, it was concluded that the black wattle is a causal invasive species in a field environment.

Keywords: Causal invasive plant; soil disturbance; steppe; grassland ecosystem.
\end{abstract}

\section{INTRODUÇÃO}

Espécies invasoras são aquelas que, não sendo originárias de um determinado ambiente ou ecossistema, nele se estabelecem após serem introduzidas pela ação humana ou por fatores naturais, 
passando a se reproduzir e dispersar nesse novo ambiente sem a ajuda direta do homem (IBGE, 2004a). As invasoras ocupam espaço de espécies nativas, tendendo a tornar-se dominantes após um período de tempo mais ou menos longo (ZILLER, 2000).

As espécies invasoras constituem-se numa séria ameaça à integridade e à sobrevivência de muitas comunidades e ecossistemas, devido à interrupção de processos biológicos, redução da biodiversidade, extinção de espécies e perdas econômicas, tendo implicações sobre a saúde e bem-estar humano e sobre o desenvolvimento sustentável (MOONEY, 2001; IBGE, 2004a).

Algumas espécies de árvores exóticas introduzidas para fins florestais e agroflorestais podem tornar-se invasoras de ecossistemas naturais e ambientes perturbados em recomposição. A magnitude do problema de invasão tem aumentado significativamente durante as últimas décadas, pelo incremento do desmatamento e mudanças no uso do solo. As espécies que causam os problemas mais graves são geralmente aquelas que têm sido amplamente plantadas por um longo tempo (RICHARDSON, 1998).

Acacia mearnsii De Wild. é uma leguminosa arbórea originária do sudeste da Austrália e da Tasmânia, onde se encontra, principalmente, nas terras baixas, nas planícies costeiras e em pequenos declives dos planaltos (BOLAND et al., 1989). É uma pioneira de rápido crescimento, eficiente fixadora de nitrogênio, com capacidade de adaptação a uma grande variedade de ambientes e habilidade de colonizar áreas alteradas e degradadas (KANNEGIESSER, 1990). Produz grande quantidade de sementes em idade jovem (STEIN; TONIETTO, 1997), que permanecem viáveis por vários anos, tendo a germinação ativada pela queima e distúrbios no solo (PIETERSE; BOUCHER, 1997). A dispersão das sementes ocorre principalmente por gravidade, estando limitada a pequenas distâncias, mas também podem ser dispersas pela água e outras formas não-intencionais (HENDERSON, 1989). Essas características biológicas capacitam a acácia-negra como potencial invasora dos ambientes em que for introduzida (HEAR, 2005).

No Brasil, a acácia-negra é plantada comercialmente no Rio Grande do Sul desde 1930, alcançando atualmente cerca de 50 municípios. A área ocupada com a espécie em 2005 foi de aproximadamente 156 mil hectares (ABRAF, 2006). É utilizada para a produção de lenha, madeira para celulose e aglomerado e constitui-se na principal fonte de casca para a indústria de taninos vegetais, adquirindo grande importância econômica e social, pois aproximadamente $60 \%$ das plantações são realizadas em pequenas propriedades rurais, beneficiando cerca de 40 mil famílias (STEIN; TONIETTO, 1997).

A acácia-negra é classificada entre as 100 espécies exóticas com maior potencial invasor do mundo (LOWE et al., 2004). É uma invasora reconhecida no Havaí (HEAR, 2005) e na África do Sul, Suazilândia e Zimbábue (HENDERSON, 2003). Numa avaliação de riscos ambientais baseada nas características biológicas e comportamento da espécie (DAEHLER et al., 2004), verificou-se que a acácia-negra pode causar significativos danos ambientais e econômicos no Havaí e em outras Ilhas do Pacífico (HEAR, 2005).

$\mathrm{Na}$ África do Sul é declarada como invasora pela legislação, podendo ser cultivada somente em áreas demarcadas sob condições controladas (HENDERSON, 2003). A invasão ocorre principalmente em beira de estradas, estepe sul-africana e margens de cursos d'água (HENDERSON, 1989). Plantas invasoras, incluindo a acácia-negra, ocupam cerca de $8 \%$ da superfície desse país, causando graves impactos ambientais aos seus ecossistemas naturais. A vazão dos rios na África do Sul reduziu-se em 6,7 $\%$, devido ao excessivo uso de água pelas árvores invasoras, sendo que um programa efetivo de controle deverá ter um custo anual de US\$ 92 milhões nos próximos 20 anos (MAITRE et al., 2002). Modelos de predição de invasão demonstram que, se nenhuma medida de controle for tomada, somente seis espécies invasoras arbóreas dos gêneros Acacia e Pinus poderão cobrir mais de 89 \% da Península Cape, com conseqüências irreversíveis sobre a biodiversidade local (HIGGINS et al., 1999).

No Brasil ainda não existem dados que comprovem o comportamento da acácia-negra como invasora de ambientes naturais. Entretanto, essa espécie normalmente é encontrada ocupando ambientes perturbados adjacentes aos cultivos, como margens de estradas. Estudos sobre o comportamento invasor da espécie nos ambientes naturais são de suma importância para identificar medidas de monitoramento e controle que evitem que o problema de invasão tome dimensões de difícil controle, como está ocorrendo na África do Sul e Havaí.

O objetivo deste trabalho foi avaliar a freqüência, a intensidade e o padrão de invasão da acácianegra em ambientes campestres e propor medidas de monitoramento e controle. 


\section{MATERIAL E MÉTODOS}

\section{Área de estudo}

Este trabalho foi realizado nos municípios de Piratini e Cristal, pertencentes a regiões ecoclimáticas distintas do Rio Grande do Sul: Encosta do Sudeste (Cristal) e Serra do Sudeste (Piratini) (FORTES, 1956). Essas regiões apresentam diferenças quanto ao solo, relevo, vegetação e clima. As áreas avaliadas na região da Encosta do Sudeste apresentam altitudes entre 50 e $100 \mathrm{~m}$ acima do nível do mar, relevo com inclinações suaves e moderadas, precipitações entre 1.200 e 1.400 mm (RIO GRANDE DO SUL, 1994) e cobertura vegetal pela transição entre floresta estacional semidecidual, estepe gramíneo-lenhosa e formações pioneiras (IBGE, 2004b). As áreas da região da Serra do Sudeste apresentam altitudes entre 250 e $350 \mathrm{~m}$ acima do nível do mar, relevo bastante diversificado, com inclinações de moderadas a fortes, precipitações entre 1.400 e 1.600 mm (RIO GRANDE DO SUL, 1994) e cobertura vegetal pela estepe arborizada, com matas de galeria formadas por remanescentes da floresta estacional semidecidual (IBGE, 2004b).

Em cada região (Cristal e Piratini) foram escolhidas duas áreas que apresentavam mais de uma rotação de cultivo de acácia-negra, uma com plantios jovens (um ano de idade em 2004) e outra com plantios adultos (cinco anos de idade em 2004). As características e uso de cada área avaliada estão apresentadas na tabela 1 .

Tabela 1. Características e uso das áreas avaliadas nas regiões de Cristal e Piratini.

Table 1. Characteristics and use of the areas evaluated in the Cristal and Piratini region.

\begin{tabular}{|c|c|c|c|c|}
\hline \multirow{2}{*}{ Características } & \multicolumn{2}{|c|}{ Cristal } & \multicolumn{2}{|c|}{ Piratini } \\
\hline & Área 1 & Área 2 & Área 3 & Área 4 \\
\hline Idade em 2004 (anos) & 1 & 5 & 1 & 5 \\
\hline Número de rotações & 5 & 4 & 2 & 2 \\
\hline Área total (ha) & 2.032 & 424 & 704 & 1.243 \\
\hline Acácia-negra (ha) & 1.196 & 237 & 325 & 502 \\
\hline Eucalipto (ha) & 5 & 1 & 4 & 5 \\
\hline Floresta (ha) & 379 & 75 & 247 & 310 \\
\hline APP em recuperação & 64 & - & 22 & - \\
\hline Campo nativo* (ha) & 10 & 30 & 12 & 239 \\
\hline Agricultura e pastagens (ha) & 68 & - & 2 & 158 \\
\hline Estradas e serviços (ha) & 58 & 6 & 18 & 19 \\
\hline Capoeira (ha) & 4 & 4 & 66 & - \\
\hline Banhado (ha) & 229 & 68 & 5 & 6 \\
\hline Outros** (ha) & 19 & 3 & 3 & 4 \\
\hline
\end{tabular}

*Inclui APP sem uso recente.

**Afloramento de rocha, sanga e açude.

\section{Ambientes avaliados}

Inicialmente foi realizado um levantamento exploratório das áreas adjacentes aos cultivos da espécie, sendo verificado que somente nos ambientes campestres encontraram-se plantas invasoras de acácia-negra. Como planta pioneira, essa espécie é incapaz de se estabelecer em ambientes sombreados de floresta ou de capoeira, mesmo existindo grandes quantidades de sementes no solo. A vegetação nos ambientes campestres é formada predominantemente por gramíneas e outras espécies herbáceas, podendo possuir árvores e arbustos nativos espaçadamente ou em pequenos capões. Foram avaliados sete ambientes campestres, conforme definição e caracterização descrita a seguir:

1. Área de Preservação Permanente (APP) em recuperação: área dentro de APP's com menor grau de hidromorfismo, utilizada com plantios de acácia-negra até há dois anos e mantida, desde então, sem intervenção para recuperação da vegetação nativa; ambiente encontrado somente em áreas adjacentes aos plantios jovens ( 1 ano de idade).

- Solos: em Cristal apresentam textura média na superfície e B textural ou lençol freático a mais de $60 \mathrm{~cm}$ de profundidade; em Piratini apresentam textura média com contato litóide entre 50 e 100 $\mathrm{cm}$ de profundidade, podendo possuir o lençol freático a mais de $50 \mathrm{~cm}$.

- Vegetação: gramíneas e ervas com 0,2 a 1,0 m de altura. 
- Perturbações: colheita do plantio de acácia-negra realizada em 2002, dois anos antes do início das avaliações deste trabalho.

- Parcelas: dimensões variáveis com área entre 300 a $800 \mathrm{~m}^{2}$.

2. APP sem uso recente: faixas de no mínimo $30 \mathrm{~m}$ às margens dos cursos d'água e $50 \mathrm{~m}$ ao redor de nascentes, sem preparo de solo há pelo menos nove anos; apresenta maior grau de hidromorfismo que a APP em recuperação.

- Solos: textura arenosa a média com alto teor de matéria orgânica na superfície, gleização ou com lençol freático na profundidade maior que $30 \mathrm{~cm}$.

- Vegetação: predomínio de gramíneas e ervas com altura entre 0,1 a 1,5 m; arbustos e árvores nativas bem esparsas, com 2,0 a $8,0 \mathrm{~m}$ de altura.

- Perturbações: erosão na borda do canal, trânsito e pastejo de animais; resíduos de colheita em parcelas com um ano de idade; e drenagem com máquinas realizada há mais de 20 anos nas parcelas da região de Cristal.

- Parcelas: demarcadas sobre o curso d'água com $10 \mathrm{~m}$ de largura e comprimento variando entre 50 e $100 \mathrm{~m}$ (500 a $1.000 \mathrm{~m}^{2}$ de área).

3. Beira de estrada: faixa de domínio de estradas municipais, localizada entre a área de rodagem e a cerca da propriedade, estando adjacente a cultivos de acácia-negra.

- Solos: em Cristal, apresentam textura média na superfície e B textural a mais de $50 \mathrm{~cm}$ de profundidade; em Piratini apresentam textura média e contato litóide a até $50 \mathrm{~cm}$ de profundidade, podendo apresentar fase pedregosa.

- Vegetação: áreas com predomínio de gramíneas e ervas com altura entre 0,2 e 1,5 m, e partes com predominância de regeneração de árvores e arbustos nativos com altura entre 1 e $6 \mathrm{~m}$.

- Perturbações: trânsito de veículos, áreas com solo exposto por máquinas e equipamentos e por queima da vegetação.

- Parcelas: comprimento de $100 \mathrm{~m}$ e largura de 2 a $10 \mathrm{~m}$ (200 a $1.000 \mathrm{~m}^{2}$ de área).

4. Afloramento de rocha: área com grande presença de rochas, impossibilitando sua utilização mecanizada, sendo mantida sem uso para o plantio de acácia-negra. Ambiente encontrado somente na região de Piratini.

- Solos: rochas na superfície ou até $50 \mathrm{~cm}$ de profundidade, solo de textura média com alto teor de matéria orgânica.

- Vegetação: predomínio de gramíneas e ervas com 0,1 a 1,5 m de altura; arbustos e árvores nativas esparsas ou em pequenos capões, com altura entre 3 e $8 \mathrm{~m}$.

- Perturbações: sem sinais de perturbações.

- Parcelas: dimensões variáveis, apresentando áreas entre 150 e $1.000 \mathrm{~m}^{2}$.

5. Borda de floresta: faixa de transição entre a floresta e o ambiente campestre. Neste trabalho, considerou-se a largura de $5 \mathrm{~m}$ para essa faixa, definindo o seu centro na primeira árvore com mais de $3 \mathrm{~m}$ de altura, ficando $2,5 \mathrm{~m}$ em direção ao interior da floresta e 2,5 m em direção ao campo.

- Solos: em Cristal apresentam textura média na superfície e B textural a mais de $60 \mathrm{~cm} \mathrm{de}$ profundidade; em Piratini apresentam contato litóide a até $70 \mathrm{~cm}$ de profundidade e textura média.

- Vegetação: predomínio de árvores nativas com altura de 4 a $15 \mathrm{~m}$ em metade da parcela e, na outra parte, predomínio de gramíneas e ervas de 0,1 a $1,5 \mathrm{~m}$ de altura, com arbustos bem esparsos.

- Perturbações: Plantio de acácia-negra entre 2 e $5 \mathrm{~m}$ (plantio adulto) ou a mais de $5 \mathrm{~m}$ (plantio jovem) da borda, resíduos de colheita e ação de máquinas na borda.

- Parcelas: largura de $5 \mathrm{~m}$ e comprimento variando entre 100 e $200 \mathrm{~m}$ (500 a $1.000 \mathrm{~m}^{2}$ de área).

6. Campo nativo: área com pastagem nativa, excetuando-se as APP's e os banhados.

- Solos: em Cristal apresentam textura média na superfície e B textural a mais de $60 \mathrm{~cm}$ de profundidade; em Piratini apresentam textura média com fase pedregosa e contato litóide a até $60 \mathrm{~cm}$ de profundidade.

- Vegetação: gramíneas e ervas nativas com 0,1 a 1,5 m de altura.

- Perturbações: pastejo por bovinos, roçagem e queima das pastagens; parcelas com preparo de solo há mais de quatro anos e outras utilizadas com acácia-negra há mais de 12 anos.

- Parcelas: 10 × $100 \mathrm{~m}$ ou 20 × $50 \mathrm{~m}\left(1.000 \mathrm{~m}^{2}\right)$, com a maior dimensão paralela ao plantio de acácia-negra. 
7. Banhado: Área encharcada a maior parte do ano e sujeita a inundações periódicas, com vegetação bem distinta e composta por espécies adaptadas a essas condições.

- Solos: acumulação de matéria orgânica na superfície, podendo apresentar gleização a mais de 60 $\mathrm{cm}$ de profundidade.

- Vegetação: gramíneas e ervas nativas com 0,1 a $1,0 \mathrm{~m}$ de altura, podendo apresentar árvores e arbustos bem esparsos com 2 a $5 \mathrm{~m}$ de altura.

- Perturbações: pastejo por bovinos; algumas parcelas da região de Cristal possuem canais de drenagem construídos há mais de 20 anos, atualmente obstruídos.

- Parcelas: dimensões variáveis, com área entre 300 e $2.000 \mathrm{~m}^{2}$.

\section{Demarcação e avaliação das parcelas}

Foram utilizados mapas de uso de solo para a alocação das parcelas em cada fazenda. Os ambientes campestres mapeados foram localizados e numerados, sendo sorteados três locais de cada tipo de ambiente para instalação de parcelas de medição. Essas parcelas foram demarcadas e dimensionadas de maneira que representassem bem o ambiente e estivessem localizadas na área de dispersão de sementes do plantio de acácia-negra adjacente ( $<30 \mathrm{~m}$ de distância). As dimensões das parcelas estão apresentadas juntamente com a descrição de cada ambiente.

Em cada local de instalação das parcelas, foi realizada a caracterização de solos, vegetação e perturbações do ambiente. As perturbações encontradas neste trabalho foram os danos provocados pela ação de maquinário e veículos, pastejo de animais introduzidos (bovinos, eqüinos e ovinos), queima da vegetação, erosão de bordas de cursos d'água e queda de árvores.

As parcelas foram avaliadas em setembro de 2004, com a contagem e medição de altura e DAP (para plantas maiores que $2 \mathrm{~m}$ de altura) de todos os indivíduos de acácia-negra existentes em cada parcela. Procurou-se também identificar sinais de perturbações no solo e na vegetação que pudessem ter favorecido a invasão dessa espécie naquele local.

Foram marcadas com etiquetas numeradas até 20 plantas invasoras de acácia-negra por parcela. Nas parcelas com mais de 20 plantas, marcaram-se 20 plantas proporcionalmente às classes de altura das plantas existentes na parcela ( $<2,0 \mathrm{~m}, 2,0$ a $4,0 \mathrm{~m}$ e $>4,0 \mathrm{~m}$ de altura). Em setembro de 2005, foi realizada uma medição de altura e DAP das plantas marcadas, sendo também verificada a quantidade de plantas mortas. As plantas marcadas não encontradas na avaliação de 2005 foram consideradas mortas.

\section{Análise dos dados}

Como as parcelas apresentavam tamanhos diferentes, os dados de contagem do número de plantas por parcela foram transformados para a área comum de 0,1 ha $\left(1.000 \mathrm{~m}^{2}\right) . \mathrm{O}$ total de plantas encontradas em cada parcela nas avaliações de 2004 e 2005 foi distribuído em três classes de altura: em estabelecimento ( $<2,0 \mathrm{~m}$ de altura), estabelecidas ( 2,0 a $4,0 \mathrm{~m}$ de altura) e adultas ( $>4 \mathrm{~m}$ de altura). Com os dados das avaliações de 2004 e 2005, foram calculados o incremento corrente anual de altura (ICAAltura) para plantas $<2,0 \mathrm{~m}$ em 2004, o incremento corrente anual de diâmetro (ICA-DAP) para plantas $\geq 2,0 \mathrm{~m}$ de altura em $2004 \mathrm{e}$ a mortalidade total de plantas e dentro de quatro classes de altura $(<0,5 \mathrm{~m}, 0,5$ a $1,9 \mathrm{~m}, 2,0$ a $4,0 \mathrm{~m}$ e $>4,0 \mathrm{~m}$ ). A mortalidade de plantas foi calculada por $m(\%)=($ plantas mortas $/$ total de plantas em 2004) $x 100$.

Foram realizadas análises de variância considerando os seguintes fatores: região ecoclimática (Cristal e Piratini), idade do plantio de acácia-negra adjacente (jovem e adulto), ambiente (APP em recuperação, APP sem uso recente, beira de estrada, afloramento de rocha, borda de floresta, campo nativo e banhado) e todas as interações possíveis entre esses fatores. Para análises estatísticas, foi empregado o programa SAS (SAS Institute, 1999), sendo utilizado o seguinte modelo matemático:

$$
\begin{aligned}
& Y_{i j k}=\mu+R_{i}+I_{j}+A_{k}+R I_{i j}+R A_{i k}+I A_{j k}+R I A_{i j k}+e_{i j k ;} \\
& Y_{i j k}=\text { Observação da região i, na idade j e no ambiente k; } \\
& \mu=\text { média geral; } \\
& R_{i}=\text { efeito da i-ésima região; } \\
& I_{j}=\text { efeito da j-ésima idade; } \\
& A_{k}=\text { efeito do k-ésimo ambiente; } \\
& R I_{i j}=\text { efeito da interação entre região e idade; } \\
& R A_{i k}=\text { efeito da interação entre região e ambiente; } \\
& I A_{i k}=\text { efeito da interação entre idade e ambiente; } \\
& R I_{i j k}=\text { efeito da interação entre região, idade e ambiente; } \\
& e_{i j k}=\text { erro associado à observação } Y_{i j k} .
\end{aligned}
$$


Foram analisadas as seguintes variáveis: número total de plantas em 2004 e 2005; número de plantas distribuídas em três classes de altura em 2004 e 2005: <2,0 m (em estabelecimento), 2,0 a 4,0 m (plantas estabelecidas) e $>4,0 \mathrm{~m}$ (plantas adultas); número de plantas adjacentes a plantios jovens e adultos por classe de altura em 2004 e 2005; mortalidade de plantas por ambiente e por classe de altura; incremento corrente anual de altura para plantas $<2 \mathrm{~m}$; e incremento corrente anual de DAP para plantas $\geq 2 \mathrm{~m}$.

Os dados foram previamente testados quanto às pressuposições de uma análise de variância, sendo analisadas a homogeneidade de variância (Teste de Levene), a normalidade dos resíduos (Teste de Shapiro-Wilks), a independência dos erros (análise gráfica) e a aditividade do modelo matemático (análise gráfica), pelo programa STATGRAPHICS (Statistical Graphics Corp, 1994). Quando uma dessas condições não foi satisfeita, procedeu-se à transformação dos dados e à identificação e retirada de dados considerados "outliers". Foi necessário realizar a transformação de todos os dados de contagem do número de plantas e de mortalidade de plantas por ambiente. Para os dados de contagem, utilizou-se a transformação $y t=\ln (y+1)$, e para mortalidade, $y t=\operatorname{arcsen} \sqrt{y / 100}$, sendo $\mathrm{y}=$ dado original e yt $=$ dado transformado (STEEL; TORRIE, 1988). Procedeu-se às análises estatísticas com os dados transformados, sendo que os valores encontrados nas análises foram retransformados à escala original para a apresentação dos resultados. A comparação de pares de médias foi realizada pelo teste t, e a de grupos de médias pelo teste de Scott-Knott (ZIMMERMANN, 2004).

Para classificar os ambientes quanto a sua suscetibilidade à invasão, foi realizada uma análise de agrupamento hierárquico, tendo como medida a distância euclidiana pelo método da ligação média (HAIR JR. et al., 2005). Para o agrupamento dos ambientes, foram utilizados os dados de número de plantas invasoras (total, em estabelecimento, estabelecidas e adultas) das avaliações de 2004 e 2005 e de crescimento de plantas.

\section{RESULTADOS E DISCUSSÃO}

$\mathrm{Na}$ avaliação realizada em setembro de 2004, foram encontradas 36,1 plantas/0,1 ha em Piratini e 27,2 plantas/0,1 ha em Cristal, não havendo diferenças significativas $(\mathrm{P}<0,05)$ entre essas regiões. A distribuição das plantas por classes de altura também foi semelhante, sendo em média encontradas 24,2 plantas em estabelecimento ( $<2,0 \mathrm{~m}$ de altura), 3,6 plantas estabelecidas $(2,0$ a 4,0 m de altura) e 4,2 plantas adultas $(>4,0 \mathrm{~m}$ de altura). Isso demonstrou uma similaridade entre as regiões ecoclimáticas estudadas quanto à suscetibilidade ambiental de invasão da espécie. A intensidade de invasão pode ser considerada baixa, especialmente considerando o reduzido número de plantas adultas encontradas nas parcelas. Em áreas invadidas após a queima da vegetação na África do Sul, foram encontradas entre 50 e 5.430 plantas de acácia-negra em parcelas de 0,1 ha (PEITERSE; BOUCHER, 1997).

A idade do plantio adjacente de acácia-negra teve influência significativa $(\mathrm{P}<0,05)$ na quantidade total de plantas invasoras, sendo maior nas parcelas próximas dos plantios jovens $(50,3$ plantas $/ 0,1$ ha em 2004) que dos plantios adultos (9,6 plantas/0,1 ha em 2004). Nas parcelas próximas de plantios jovens, predominaram plantas em estabelecimento $(<2,0 \mathrm{~m}$ de altura), enquanto nas áreas adjacentes aos plantios adultos predominaram plantas adultas $(>4,0 \mathrm{~m}$ de altura). Os plantios adultos estavam em plena produção de sementes, no entanto a quantidade de plantas em estabelecimento encontrada nos ambientes adjacentes, localizados a menos de $30 \mathrm{~m}$ desses plantios, foi de somente 0,8 e 0,2 plantas/0,1 ha para as avaliações de 2004 e 2005, respectivamente. Dessa forma, a invasão da espécie a ambientes não depende unicamente da disponibilidade de sementes no solo. As parcelas de plantios jovens avaliadas neste trabalho apresentavam mais de um ciclo de cultivo da acácia-negra, possibilitando a formação de um banco de sementes no solo das áreas adjacentes. Existindo, então, disponibilidade de sementes, outros fatores foram preponderantes para a invasão da acácia-negra.

A invasão da acácia-negra aos ambientes esteve relacionada às operações florestais ocorridas durante o período que se inicia com a colheita florestal e que se estende até a implantação da nova rotação de cultivo. A derrubada das árvores e as operações com maquinários e veículos fora das áreas de cultivo causam perturbações no solo, propiciando condições para a germinação de sementes e o estabelecimento de plântulas de acácia-negra - por isso foram encontradas maiores quantidades de plantas em estabelecimento nas áreas próximas dos plantios jovens ( 1 ano de idade). Durante o período de crescimento do plantio (segundo ano até a colheita), não foram realizadas operações florestais que envolveram máquinas e equipamentos, o que reduziu as perturbações do solo àquelas de origem natural, limitando a ocorrência de novas invasões. A freqüência de invasão da acácia-negra aos ambientes ocorreu 
ao mesmo tempo em que foram realizadas as operações de colheita e implantação da nova rotação de cultivo.

Os totais de plantas invasoras de acácia-negra encontrados nos ambientes em 2004 e 2005 permitiu classificá-los $(\mathrm{P}<0,05)$, pelo teste de Scott-Knott, em três grupos de invasão (Figura 1). $\mathrm{O}$ ambiente com o maior número de invasoras nos dois anos de avaliação foi a APP em recuperação, que apresentou 151,3 plantas/0,1 ha em 2004 e 89,8 plantas/0,1 ha em 2005. Uma redução foi significativa $(\mathrm{P}<0,05)$, devido à mortalidade de $42,3 \%$ no período. $\mathrm{O}$ maior número de plantas invasoras encontrado nesse ambiente deveu-se à existência de banco de sementes, mas principalmente à grande perturbação do solo ocasionada pela colheita realizada dois anos antes do início das avaliações. A invasão foi na forma de adensamento (reboleiras), com até 8,0 plantas $/ \mathrm{m}^{2}$ nos locais com solos mais expostos, e dispersa nas áreas com menor perturbação.

Num segundo grupo de invasão, encontram-se o afloramento de rocha, beira de estradas e borda de floresta, que apresentaram, respectivamente, 50,2, 47,7 e 25,1 plantas/0,1 ha na avaliação de 2004 e 39,0, 25,8 e 18,2 plantas/0,1 ha, em 2005 - uma redução significativa $(\mathrm{P}<0,05)$ para beira de estrada e borda de floresta e não significativa para o afloramento de rocha (Figura 1). A mortalidade de plantas no período foi similar para os três ambientes, com 20,0, 18,8 e 16,2 \% para beira de estrada, afloramento de rocha e borda de floresta, respectivamente. No afloramento de rocha, a invasão ocorreu de forma dispersa ou em pequenos aglomerados em locais próximos de rochas expostas, favorecida pela quebra da dormência das sementes com o aquecimento das rochas pela radiação solar. A invasão na beira de estradas foi de forma espalhada, sendo beneficiada pelas constantes perturbações causadas pelo trânsito de máquinas e veículos, bem como por queimadas acidentais. Na borda de floresta, a invasão foi esparsa, somente ocorrendo na parte da parcela com vegetação herbácea e nos locais com alguma perturbação, especialmente as provocadas por máquinas durante o encoivaramento dos resíduos de colheita.

O terceiro grupo de invasão foi formado pela APP sem uso recente, campo nativo e banhado, que apresentaram $<11,0$ plantas/0,1 ha em 2004 e $<8,0$ plantas/0,1 ha em 2005 (Figura 1). A redução do número de plantas entre 2004 e 2005 foi significativa $(\mathrm{P}<0,05)$ somente para o campo nativo, devido a maior $(\mathrm{P}<0,05)$ mortalidade de plantas $(37,6 \%)$ que a da APP sem uso recente $(20,6 \%)$ e do banhado $(9,5 \%)$. A invasão na APP sem uso recente foi bem dispersa, ocasionada pela erosão de barrancos do canal de drenagem, perturbações por operações florestais e trânsito de animais. No campo nativo, a invasão foi por plantas isoladas, sendo favorecida pela queimada das pastagens, pelo sobrepastejo e pela presença de grande quantidade de pedras em algumas parcelas (quebra de dormência pelo aquecimento). No banhado, a invasão ocorreu por plantas isoladas em áreas perturbadas e sobre "murundus" formados por formigas cortadeiras, que também se encarregaram de transportar as sementes.

O maior número de plantas adultas ( $>4,0 \mathrm{~m}$ de altura) na avaliação de 2005 foi verificado na APP em recuperação e no afloramento de rocha, com 29,7 e 25,0 plantas/0,1 ha, respectivamente (Figura 1). Em seguida, encontra-se a beira de estrada (12,1 plantas $/ 0,1$ ha) e borda de floresta $(8,7$ plantas $/ 0,1$ ha $)$ e por último o grupo formado pela APP sem uso recente $(3,3$ plantas $/ 0,1$ ha), banhado ( 1,9 plantas $/ 0,1$ ha) e campo nativo $(0,8$ plantas $/ 0,1$ ha). Uma quantidade considerável de sementes germinou e se estabeleceu, mas somente uma pequena parte dessas plântulas foi capaz de alcançar a fase adulta.

A distribuição do número de plantas por classes de altura foi similar para todos os ambientes estudados nas duas avaliações realizadas. Em 2004, verificou-se que nas parcelas adjacentes a plantios jovens ( 1 ano de idade) prevaleceram $(\mathrm{P}<0,05)$ plantas em estabelecimento $(<2,0 \mathrm{~m}$ de altura), enquanto que, para as parcelas próximas de plantios adultos ( 5 anos de idade), a maioria das plantas encontradas foi de adultas (>4,0 $\mathrm{m}$ de altura) (Figura 2). As parcelas próximas dos plantios adultos mantiveram em 2005 a mesma distribuição de classes de altura da avaliação de 2004. No entanto, as parcelas adjacentes aos plantios jovens apresentaram mudanças substanciais nessa distribuição na avaliação de 2005, com todas as classes apresentando um número similar de plantas $(\mathrm{P}<0,05)$. Houve uma diminuição do número de plantas em estabelecimento e um aumento das plantas estabelecidas e adultas, devido à maior mortalidade das plantas em estabelecimento (Figura 3), ao crescimento das plantas que alcançaram as classes superiores de altura e por não ter havido novas invasões no período de avaliação. Esses resultados confirmam que a freqüência de estabelecimento de plantas invasoras de acácia-negra está relacionada com as perturbações do ambiente ocorridas durante a colheita e preparo da área para o novo plantio. Não havendo perturbações do ambiente campestre, praticamente não há o estabelecimento de plantas invasoras de acácia-negra, mesmo existindo disponibilidade de sementes no solo. 


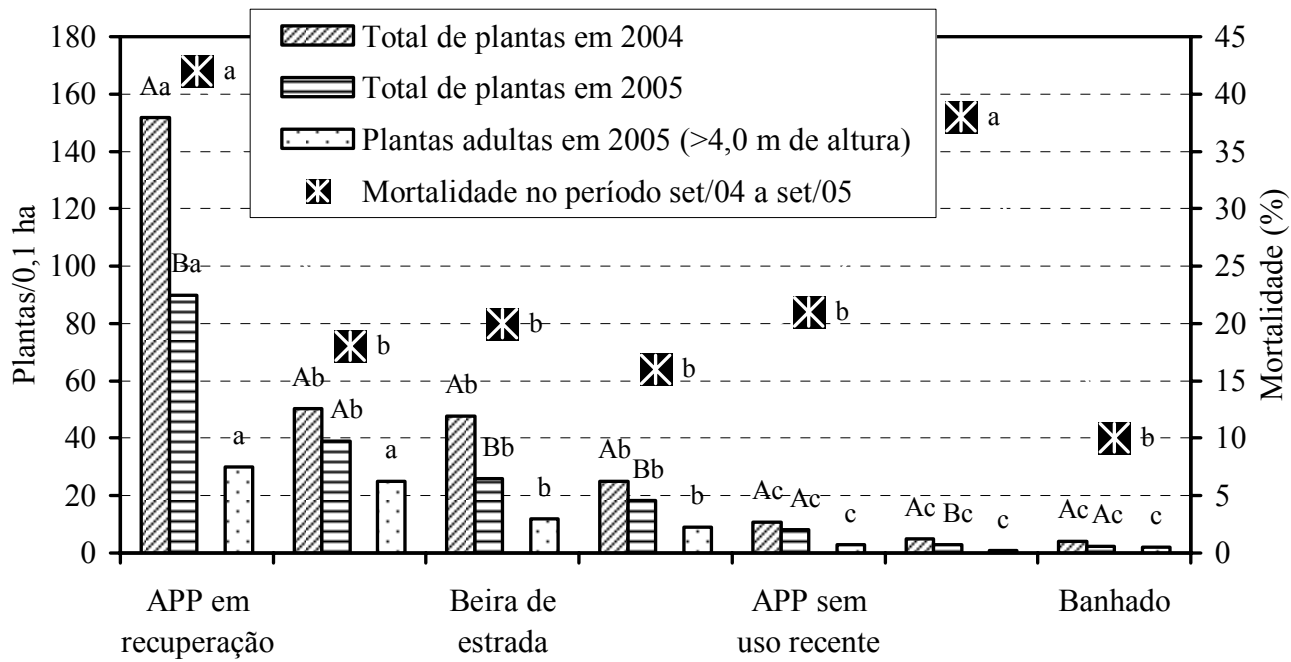

Figura 1. Número total e mortalidade de plantas invasoras de acácia-negra em ambientes campestres adjacentes a plantios dessa espécie.

Figure 1. Total number and mortality of the black wattle invaders plants in field environments located near of plantations this species.

Letras maiúsculas diferentes, para comparar o total de planta em 2004 e 2005 dentro do mesmo ambiente, diferem entre si pelo teste $\mathrm{t}(\mathrm{P}<0,05)$. Letras minúsculas diferentes, para comparar a mesma variável entre os ambientes, diferem entre si pelo teste de Scott-Knott $(\mathrm{P}<0,05)$.

A mortalidade média de invasoras de acácia-negra no período de setembro/2004 a setembro/2005 foi de $35,8 \%$, sendo maior $(\mathrm{P}<0,05)$ nas classes de menores alturas, atingindo $80,4 \%$ nas plantas $<0,5 \mathrm{~m}$ de altura, $14,0 \%$ nas plantas entre 0,5 a $1,9 \mathrm{~m}$ de altura, $6,8 \%$ nas plantas entre 2,0 a 4,0 $\mathrm{m}$ de altura e de 5,5\% nas plantas $>4,0 \mathrm{~m}$ de altura (Figura 3). A mortalidade observada nas plantas $<2 \mathrm{~m}$ de altura foi maior devido à competição causada pela recomposição da vegetação nativa e morte de plantas suprimidas nos locais em que a invasão ocorreu de forma adensada. No campo nativo, a mortalidade de plantas foi provocada pelo pastejo de bovinos (plantas $<2,0 \mathrm{~m}$ de altura); na borda de floresta e beira de estradas foi ocasionada pela competição com a vegetação arbórea nativa; e no afloramento de rocha, APP sem uso recente e banhado foi causada pela inaptidão do local invadido para a manutenção de árvores invasoras dessa espécie, como solo muito raso ou lençol freático pouco profundo.

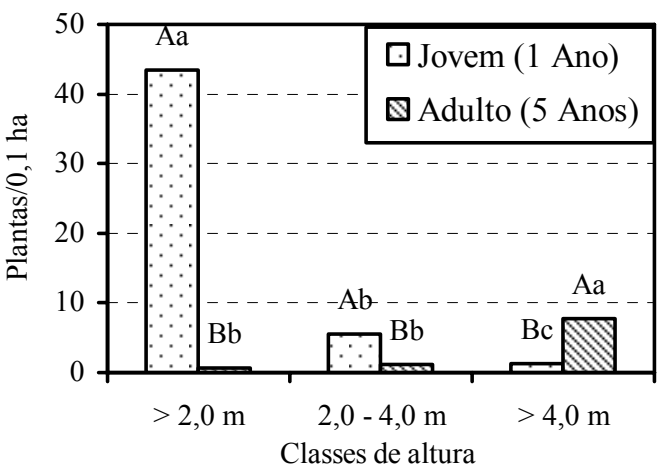

2004

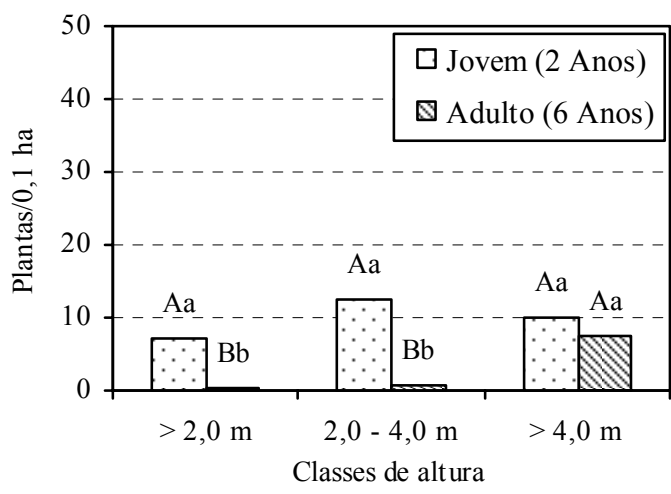

2005

Figura 2. Distribuição do número de plantas invasoras de acácia-negra por classes de altura e idade do plantio adjacente nas avaliações de 2004 e 2005.

Figure 2. Number of black wattle invaders plants in the different size classes and age of the adjacent plantation at the 2004 and 2005 evaluation.

Letras maiúsculas diferentes, para comparar a idade do plantio (jovem e adulto) dentro da mesma classe de altura, diferem entre si pelo teste $\mathrm{t}(\mathrm{P}<0,05)$. Letras minúsculas diferentes, para comparar a mesma idade do plantio entre as classes de altura, diferem entre si pelo teste de Scott-Knott $(\mathrm{P}<0,05)$. 
$\mathrm{Na}$ avaliação realizada em setembro de 2005, observou-se que grande parte das plantas em estabelecimento $(<2,0 \mathrm{~m}$ de altura) estava suprimida pela competição com a vegetação nativa, apresentando um crescimento menor que $1,0 \mathrm{~m}$ de altura no período de um ano. Considerando o total de plantas mortas e plantas suprimidas, que não deverão se estabelecer, verifica-se que $74,0 \%$ das plantas em estabelecimento encontradas na avaliação de 2004 não atingirão a fase adulta (Figura 3). Isso confirma que a mortalidade de plantas foi a principal causa da menor quantidade de plantas encontradas próximas dos plantios adultos.
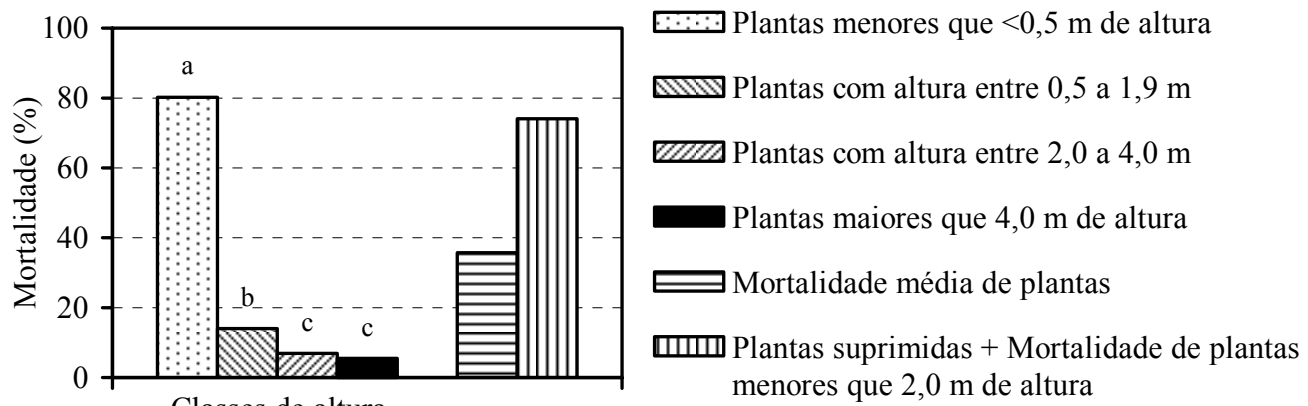

Figura 3. Mortalidade média em quatro classes de altura de plantas invasoras de acácia-negra no período de setembro/2004 a setembro/2005.

Figure 3. Average mortality of four size height classes of black wattle invader plants in the period from september/2001 to september/2005.

Letras diferentes para classes de altura diferem entre si pelo teste de $\operatorname{Scott}-\operatorname{Knott}(\mathrm{P}<0,05)$.

O crescimento das plantas invasoras de acácia-negra apresentou diferenças significativas $(\mathrm{P}<0,05)$ nas regiões estudadas. As plantas em estabelecimento $(<2,0 \mathrm{~m}$ de altura) apresentaram crescimento médio em altura de $1,7 \mathrm{~m}$ /ano para Piratini e de 1,2 m/ano para Cristal. Nas plantas estabelecidas e adultas ( $\geq 2,0 \mathrm{~m}$ de altura), o incremento de diâmetro foi de 2,4 cm/ano em Piratini e de $1,7 \mathrm{~cm} /$ ano em Cristal. Essas diferenças foram em função das características ambientais de cada região, especialmente as condições de solo (ver descrição dos ambientes). Em testes com as mesmas procedências, Mora (2002) encontrou uma produtividade em Piratini 58,3 \% superior à obtida em Cristal, tendo atribuído essa diferença às melhores condições ambientais de Piratini.

$\mathrm{O}$ crescimento em altura das plantas em estabelecimento foi maior $(\mathrm{P}<0,05)$ nos ambientes de APP em recuperação, afloramento de rocha e beira de estrada (Figura 4). Para as plantas estabelecidas e adultas ( $\geq 2,0 \mathrm{~m}$ de altura), observaram-se os maiores crescimentos em diâmetro nos ambientes de campo nativo, APP sem uso recente, APP em recuperação e afloramento de rocha. As diferenças de crescimento observadas entre os ambientes deveram-se às características de solos, à competição com vegetação nativa e ao consumo das plantas por animais. O menor crescimento observado no banhado foi devido à condição de solo encharcado a maior parte do ano, na borda de floresta foi pela competição com a vegetação arbórea nativa e o das plantas em estabelecimento na APP sem uso recente foi pela competição com plantas herbáceas. $\mathrm{O}$ baixo crescimento observado nas plantas em estabelecimento do campo nativo foi devido ao consumo das folhas por bovinos. O contrário ocorreu com plantas estabelecidas e adultas ( $\geq 2 \mathrm{~m}$ de altura), cujas folhas os animais não conseguem consumir.

Espécies pioneiras (ou heliófitas efêmeras), como a acácia-negra, apresentam como principais características a rápida colonização de ambientes abertos; requerimento de luz direta; produção numa idade precoce de uma grande quantidade de sementes amplamente disseminadas, formando bancos de sementes no solo; germinação rápida, mas que requer indução (fotoblástica ou termoblástica); e alta capacidade fotossintética, proporcionando um crescimento rápido (PIÑA-RODRIGUES et al. 1990; FINEGAN, 1993). Essas características ditam o padrão de invasão da acácia-negra a ambientes campestres naturais e em recomposição.

A acácia-negra apresenta uma grande produção de sementes, podendo alcançar $0,7 \mathrm{~kg}$ por árvore aos dez anos de idade - $1 \mathrm{~kg}$ contém em média 65.000 sementes, com germinação entre 85 e $90 \%$ (STEIN; TONIETTO, 1997). No entanto, sua dispersão parece estar limitada a áreas bem próximas dos plantios ou ao transporte por ação do homem (intencional ou não). As sementes não possuem atrativos

FLORESTA, Curitiba, PR, v. 37, n. 2, mai./ago. 2007. 
para vetores (aves e mamíferos) e nem adaptação para disseminação pelo vento (HEAR, 2005). Formigas cortadeiras transportam sementes até o formigueiro para utilização do arilo. No entanto, somente no ambiente de banhado foram encontradas plantas invasoras sobre formigueiros. A maioria dos formigueiros é construída sob vegetação arbórea, o que inviabiliza o estabelecimento de invasoras dessa espécie. Fortes chuvas em áreas com declives podem transportar as sementes para áreas mais longe dos plantios. Neste trabalho, verificaram-se plantas invasoras ao longo de cursos d'água (APP's) até a uma distância de $50 \mathrm{~m}$ da fonte de sementes.

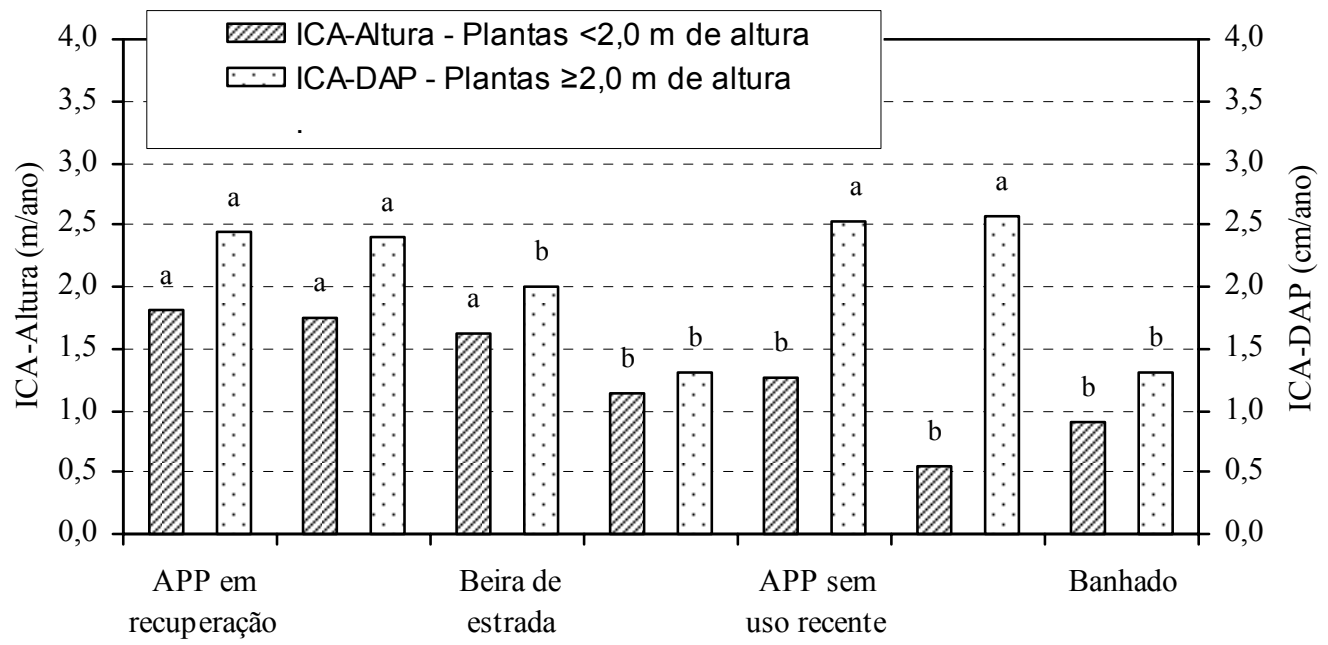

Figura 4. Incremento Corrente Anual (ICA) em Altura e DAP de plantas invasoras de acácia-negra no período de setembro/2004 a setembro/2005.

Figure 4. Current annual increment in height and DBH of black wattle invaders plants in the period from september/2001 to september/2005.

Letras minúsculas diferentes, para comparar a mesma variável entre os ambientes, diferem entre si pelo teste de ScottKnott $(\mathrm{P}<0,05)$.

As áreas avaliadas com o solo totalmente coberto pela vegetação herbácea não apresentavam plantas invasoras de acácia-negra, mesmo em locais bem próximos $(<30 \mathrm{~m})$ de plantios em plena produção de sementes. Dois fatores, não excludentes, podem estar contribuindo para que isso ocorra. O primeiro é a necessidade de indução da germinação das sementes (quebra de dormência), seja através do choque térmico (queima da vegetação), seja pela qualidade da radiação (luz direta) (PIETERSE; BOUCHER, 1997). Dessa forma, áreas mantidas com boa cobertura de solo não teriam fatores para a indução da germinação das sementes da acácia-negra. Isso explicaria a maior presença de plantas invasoras, encontrada neste trabalho, no ambiente de afloramento de rocha, pois tanto o aquecimento das pedras como a luz direta nas sementes sobre as rochas podem induzir sua germinação e iniciar a invasão do ambiente.

Outro fator é a competição com a vegetação herbácea. Plântulas de espécies pioneiras requerem luz direta para seu crescimento, pois apresentam reservas nutricionais pequenas, não sendo capazes de sustentar seu crescimento inicial (PIÑA-RODRIGUES et al., 1990). Neste trabalho, quase que a totalidade das plantas invasoras em estabelecimento $(<2 \mathrm{~m}$ de altura) foi encontrada em locais com algum sinal de perturbação na vegetação herbácea, permitindo que a radiação solar atingisse o solo e as plântulas na fase inicial de estabelecimento. No Havaí também é citada a necessidade de distúrbios para o estabelecimento da invasão da acácia-negra (HEAR, 2005). Áreas ripárias da África do Sul são particularmente propensas à invasão devido à dispersão de sementes e aos distúrbios causados por inundações (MAITRE et al., 2002).

A intensidade de invasão das áreas perturbadas está relacionada com o nível de exposição do solo. Áreas com solos mais expostos (APP em recuperação) apresentaram um maior número de plantas em estabelecimento que as áreas com menor exposição (APP sem uso recente). No entanto, a competição (intra e interespecífica) reduziu drasticamente a população de invasoras nos anos seguintes da invasão. Neste trabalho, observou-se que a quantidade de plantas adultas encontradas nos plantios adultos aos seis anos de idade (avaliação de 2005) foi em média 14,9 \% do total de plantas no plantio jovens com um ano de idade 
(avaliação de 2004), resultado da alta mortalidade, que pode alcançar a 74,0 \% das plantas em estabelecimento nos três primeiros anos após o início da invasão (Figura 3). Para invasoras de acácia-negra em área queimada, Pieterse e Boucher (1997) citam uma taxa de mortalidade de $90 \%$ aos dois anos de idade.

A intensidade de invasão da acácia-negra nos ambientes campestres observada neste trabalho é inferior às encontradas em diversas regiões da África do Sul (HENDERSON; MUSIL, 1984; HENDERSON, 1989; DYE e POULTER, 1995). Isso provavelmente ocorreu devido ao menor tempo de cultivo da espécie no Rio Grande do Sul e à maior diversidade da vegetação dos ambientes avaliados. A suscetibilidade dos ambientes à invasão estão relacionados com o tempo de cultivo da espécie na região (RICHARDSON, 1998), com a diversidade da vegetação nativa, com a ocorrência de competidores, predadores e parasitas e com o grau de perturbação do ecossistema (ZILLER, 2001).

A freqüência de invasão esteve relacionada com as operações de colheita e plantio, período em que ocorreram maiores perturbações nos ambientes adjacentes aos plantios. Com a recomposição da vegetação nativa, ocorreu grande mortalidade de plantas, praticamente não havendo novas invasões.

Os ambientes estudados foram classificados, com base nos dados do número de plantas invasoras e crescimento de plantas, pela análise de agrupamento, em cinco grupos de suscetibilidade à invasão da acácia-negra (Figura 5):

- Alta susceptibilidade: bom crescimento de plantas e alta quantidade de invasoras em estabelecimento, das quais, apesar da maior mortalidade registrada nesse ambiente, uma grande quantidade das plantas chegou à fase adulta. Nesse grupo classifica-se a APP em recuperação.

- Média susceptibilidade: bom crescimento das plantas, porém o número de invasoras, tanto em fase de estabelecimento como na fase adulta foi menor que o agrupamento anterior. Nessa classe agruparam-se o afloramento de rocha e a beira de estrada.

- Baixa susceptibilidade: baixo crescimento das plantas e pequena quantidade de plantas nas fases de estabelecimento e adulta. Nesse grupo classificaram-se a borda de floresta e a APP sem uso recente.

- Baixíssima susceptibilidade: baixo crescimento das plantas, especialmente das invasoras em estabelecimento, e muito baixo número de invasoras, tanto na fase jovem como na adulta, devido às limitações de solo ou controle da invasão por consumo animal. Nesse agrupamento estão o campo nativo e o banhado.

Os resultados obtidos neste trabalho indicaram que acácia-negra pode ser considerada para as condições ambientais e de plantios do Rio Grande do Sul uma invasora causal, por não ser capaz de se estabelecer e competir em ambientes sem a ação de perturbações no solo. Segundo Richardson et al. (2000), plantas introduzidas num ambiente passam por diversas fases até tornarem-se invasoras: depois da introdução de uma espécie (estabelecimento de uma população adulta), as plantas reproduzem novos indivíduos (colonização), dispersam-se e formam novas colônias (naturalização), para posteriormente tornar-se invasora, podendo ser transformadora de ambientes. Para cada fase é necessário ultrapassar barreiras geográficas (introdução), biológicas (reprodução e dispersão) e ambientais (condições para o crescimento, dispersão, colonização e dominação da vegetação). Tendo em vista a terminologia proposta por esses autores, a acácia-negra nos ambientes campestres do Rio Grande do Sul poderia ser considerada uma planta invasora, porém adicionou-se o adjetivo "causal" para indicar a necessidade de uma causa, os distúrbios nos solos, para o estabelecimento de plantas nos ambientes naturais, bem como para o recrutamento de novos indivíduos nas áreas invadidas.

\section{Monitoramento e controle da invasão}

Mesmo considerando a acácia-negra uma invasora causal para as condições de ambientes campestres do Rio Grande do Sul, torna-se necessário tomar medidas de monitoramento e controle, para evitar que a seleção natural possa gerar indivíduos mais aptos para colonizar os ambientes naturais da região. Na África do Sul, a introdução dessa espécie ocorreu em 1864 (SHERRY, 1971), porém somente 120 anos depois foram publicados os primeiros trabalhos relatando casos de invasão da acácia-negra a ambientes naturais de estepe e áreas ripárias (HENDERSON; MUSIL, 1984; HENDERSON, 1989). Dessa forma, é necessário manter as áreas não plantadas livres da presença da acácia-negra, impedindo que a expansão da invasão evolua para a fase de transformação de ecossistemas (RICHARDSON et al., 2000), situação de difícil controle, como ocorreu na África do Sul. 
A redução das perturbações nas áreas não utilizadas a níveis mínimos é uma meta a ser buscada pelos produtores. A principal causa de perturbações observada neste trabalho foi o tráfego de máquinas e equipamentos. Os operadores de máquinas devem ser instruídos a evitar o trânsito nas áreas que não serão utilizadas para o cultivo da espécie, minimizando assim a possibilidade de invasão.

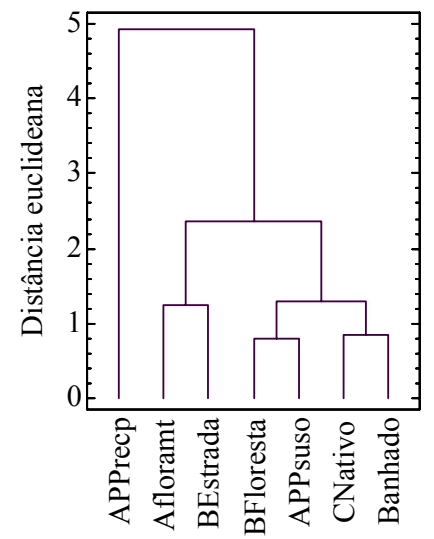

Figura 5. Dendrograma de agrupamento hierárquico da susceptibilidade dos ambientes à invasão da acácia-negra.

Figure 5. Dendrogram for the hierarchical cluster of the environments susceptility for black wattle invasion plants.

APPrecp: APP em recuperação; Afloramt: afloramento de rocha; BEstrada: beira de estrada; BFloresta: borda de floresta; APPsuso: APP sem uso recente; CNativo: campo nativo.

Na tabela 2 são sugeridas medidas de monitoramento e controle para os ambientes avaliados. Para áreas com invasão em adensamentos (APP em recuperação) recomenda-se a eliminação das plantas invasoras no primeiro ano de crescimento, visando favorecer a recomposição da vegetação nativa. Para ambientes com plantas invasoras espalhadas e dispersas (afloramento de rocha, borda de floresta e APP sem uso), recomenda-se o corte de todas invasoras até o terceiro ano, antes do início da produção de sementes das plantas. Isso evitaria a seleção e reprodução de indivíduos mais aptos para esses ambientes. Para ambientes em que a invasão é rara, com plantas bem isoladas (campo nativo e banhado), recomendase o corte das plantas adultas ao final de cada rotação de cultivo.

Para o ambiente de beira de estrada que, por sua natureza, é constantemente perturbado, recomenda-se somente o corte das invasoras no final de cada rotação. Esse foi o único ambiente em que se observaram plantas invasoras de acácia-negra fora da área de influência direta dos cultivos dessa espécie. Por isso os produtores devem buscar o controle dos indivíduos invasores, para a eliminação de possíveis fontes de dispersão de sementes. Observações de campo nos ambientes invadidos deste trabalho indicaram que plantas de acácia-negra com mais de $2 \mathrm{~m}$ de altura cortadas a até $10 \mathrm{~cm}$ do solo não emitiram rebrota, portanto o corte manual ou mecânico pode ser utilizado para eliminação das plantas invasoras desses ambientes.

\section{CONCLUSÕES}

A invasão da acácia-negra a ambientes campestres está condicionada a perturbações e distúrbios no solo, ou seja, há a necessidade de exposição do solo a plena luz, devendo por isso ser considerada uma invasora causal de áreas naturais e em recomposição.

A maior freqüência de invasões ocorre durante as operações de colheita e implantação da nova rotação, devido às perturbações que ocorrem nesse período. O estabelecimento de novas invasões é insignificante durante o período de crescimento do plantio.

A intensidade de invasão está relacionada com o grau de perturbação do ambiente campestre: quanto maior for a exposição do solo, maior será a quantidade de plantas invasoras de acácia-negra.

A APP em recuperação apresenta alta susceptibilidade à invasão da acácia-negra; o afloramento de rocha e beira de estrada, média suscetibilidade; borda de floresta e A APP sem uso recente, baixa susceptibilidade; e campo nativo e banhado, baixíssima suscetibilidade. 
Tabela 2. Causas e padrões de invasão da acácia-negra e medidas para monitoramento e controle.

Table 2. Causes and patterns of black wattle invasion and methodologies for monitoring and control.

\begin{tabular}{|c|c|c|c|c|}
\hline Ambiente & Causa de invasão & Padrões de invasão & Monitoramento & Controle \\
\hline $\begin{array}{l}\text { APP em } \\
\text { recuperação }\end{array}$ & $\begin{array}{l}\text { Perturbações no solo } \\
\text { durante a colheita da } \\
\text { rotação anterior. }\end{array}$ & $\begin{array}{l}\text { Forma adensamentos nas } \\
\text { áreas com solo exposto. } \\
\text { Plantas dispersas nos locais } \\
\text { pouco perturbados. }\end{array}$ & $\begin{array}{l}\text { Anualmente, até a } \\
\text { recomposição da } \\
\text { vegetação nativa. }\end{array}$ & $\begin{array}{l}\text { Corte das reboleiras até um } \\
\text { ano de idade. Corte de plantas } \\
\text { isoladas até o terceiro ano após } \\
\text { o início da rotação. }\end{array}$ \\
\hline $\begin{array}{l}\text { Beira de } \\
\text { estrada }\end{array}$ & $\begin{array}{l}\text { Queima da vegetação. } \\
\text { Perturbações no solo pelo } \\
\text { trânsito de máquinas e } \\
\text { veículos }\end{array}$ & $\begin{array}{l}\text { Plantas espalhadas nos } \\
\text { locais perturbados. }\end{array}$ & Final da rotação. & $\begin{array}{l}\text { Corte das plantas invasoras na } \\
\text { colheita. }\end{array}$ \\
\hline $\begin{array}{l}\text { Borda de } \\
\text { floresta }\end{array}$ & $\begin{array}{l}\text { Perturbações no solo pelo } \\
\text { coivaramento dos } \\
\text { resíduos de colheita. }\end{array}$ & $\begin{array}{l}\text { Plantas bem esparsas, } \\
\text { somente na parte de } \\
\text { vegetação herbácea da } \\
\text { parcela. }\end{array}$ & $\begin{array}{l}\text { Terceiro ano da } \\
\text { rotação. }\end{array}$ & $\begin{array}{l}\text { Corte das plantas invasoras até } \\
\text { o terceiro ano após o início da } \\
\text { rotação. }\end{array}$ \\
\hline Campo nativo & $\begin{array}{l}\text { Sobrepastoreio. Quebra } \\
\text { de dormência pela } \\
\text { queima da pastagem e } \\
\text { por presença de pedras. }\end{array}$ & $\begin{array}{l}\text { Plantas isoladas em locais } \\
\text { perturbados ou sobre } \\
\text { pedras. }\end{array}$ & Final da rotação. & $\begin{array}{l}\text { Corte das plantas estabelecidas } \\
\text { e adultas ( } \geq 2,0 \text { m de altura) na } \\
\text { colheita da rotação. Animais } \\
\text { consomem folhas das plantas } \\
\text { jovens. }\end{array}$ \\
\hline Banhado & $\begin{array}{l}\text { "Murundus" formados } \\
\text { por formigas cortadeiras. } \\
\text { Perturbação por } \\
\text { operações florestais. }\end{array}$ & $\begin{array}{l}\text { Plantas isoladas sobre } \\
\text { "murundus" ou em áreas } \\
\text { perturbadas, sem formar } \\
\text { sucessão. }\end{array}$ & Final da rotação. & $\begin{array}{l}\text { Corte das plantas adultas ( }>4,0 \\
\mathrm{~m} \text { de altura) na colheita da } \\
\text { rotação. }\end{array}$ \\
\hline
\end{tabular}

A regeneração natural da vegetação nas áreas perturbadas ocasiona uma alta mortalidade de plantas em estabelecimento $(<2,0 \mathrm{~m}$ de altura) nos anos seguintes à invasão. Após a recuperação da cobertura vegetal do ambiente, a ocorrência de novas invasões é rara.

Recomenda-se a adoção de medidas para evitar perturbações aos ambientes não utilizados por cultivos e a adoção de medidas de monitoramento e controle das plantas invasoras, visando impedir sua expansão para além dos limites de cultivo da espécie.

\section{REFERÊNCIAS}

ABRAF. Anuário estatístico da ABRAF: ano base 2005. Brasília,2006. 80 p.

BOLAND, D. J.; BROOKER, M.I.H.; CHIPPENDALE, G. M.; HALl, N.; HYLAND, B. P. M.; JOHNSTON, R. D.; KLEINIG, D. A.; TURNER, J. D. Black Wattle. In: Melbourne: Thomas Nelson/CSIRO, 1984. p. 162-163. Forest trees of Australia.

DYE, P. J.; POULTER, A. G. A field demonstration of the effect on streamflow of clearing invasive pine and wattle trees from a riparian zone. South African Forestry Journal, Pretoria, n. 173. p. 27-30, 1995.

FINEGAN, B. Los gremios de especies forestales. In: BASES ecológicas para la silvicultura. Turrialba: CATIE, 1993. p. 1-35.

FORTES, A. B. Aspectos fisiográficos, demográficos e econômicos do Rio Grande do Sul. Porto Alegre: Livraria do Globo, 1956.

HAIR JR, J. F.; ANDERSON, R. E.; TATHAM, R. L.; BLACK, W.C. Análise multivariada de dados. Tradução: A.S.Sant'Anna e A. Chaves Neto. 5. ed. Porto Alegre: Bookman, 2005.

HEAR - Hawaiian Ecosystems at Risk Project. Acacia mearnsii. Disponível em: $<$ http://www.hear.org/pier/species/acacia_mearnsii.htm>. Acesso em: 22/02/2005. 
HENDERSON, L.; MUSIL, K. J. Exotic woody plant invaders of the Transvaal. Bothalia, Pretoria, v. 15, n. $1 / 2$, p. 297-313. 1984.

HENDERSON, L. Invasive alien woody plants of Natal and the north-eastern Orange Free State. Bothalia, Pretoria, v. 19, n. 2, p. 237-261, 1989.

HENDERSON, L. The Southern African Plant Invaders Atlas (SAPIA) database and bibliography. In: MACDONALD, I. A. W. (Ed.). Invasive Alien Species in Southern Africa: National Reports e Directory of Resources. Cape Town: Global Invasive Species Programme, 2003. p. 91-125.

MORA, A. L. Aumento da produção de sementes geneticamente melhoradas de Acacia mearnsii De Wild. (Acácia negra) no Rio Grande do Sul. 140 f. Tese (Doutorado em Ciências Florestais) - Setor de Ciências Agrárias, Universidade Federal do Paraná, Curitiba, 2002.

HIGGINS, S. I.; RICHARDSON, D. M.; COWLING, R. M.; TRINDER-SMITH, T. H. Predicting the Landscape-Scale Distribution of Alien Plants and Their Threat Diversity. Conservation Biology, Boston, v. 13, n. 2, p. 303-313, apr. 1999.

IBGE. Espécies invasoras. In: Indicadores de desenvolvimento sustentável: Dimensão ambiental: biodiversidade. Rio de Janeiro: IBGE, 2004a. p. 124-134. Disponível em: <http://www.ibge.gov.br/home/ geociencias/recursosnaturais/ids/biodiversidade.pdf>. Acesso em: 22/02/2005.

IBGE. Mapa de vegetação do Brasil. Rio de Janeiro: IBGE, 2004b. Disponível em: $<$ http://www.ibge.gov.br/servidor_arquivos_geo> Diretório: mapas/tematicos/mapas_murais/vegetacao. pdf. Acesso em: 14/02/2006.

KANNEGIESSER, U. Apuntes sobre algunas acacias australianas: Acácia mearnsii De Willd. Ciência e Investigación Forestal, Santiago de Chile, v. 4, n. 2, p. 198-212, 1990.

LOWE, S.; BROWNE, M.; BOUDJELAS, S.; De POORTE, M. 100 of the World's Worst Invasive Alien Species: a selection from the Global Invasive Species Database. Auckland: ISSG/SSC/IUCN, 2004. 12 p.

MAITRE, D. C. Le; WILGEN, B. W. van; GELDERBLOM, C. M.; BAILEY, C.; CHAPMAN, R. A. Invasive alien trees and water resources in south Africa: case studies of costs and benefits of management. Forest Ecology and Management, Amsterdam, v. 160, p. 143-159. 2002

MOONEY, H. Invasive Alien Species: the nature of the problem. In: ASSESSMENT and management of alien species that threaten ecosystems, habitats and species. Montreal: Secretariat of the Convention on Biological Diversity, 2001. p.1-2.

MORA, A. L. Aumento da produção de sementes geneticamente melhoradas de Acacia mearnsii De Wild. (Acácia-negra) no Rio Grande do Sul. 140 f. Tese (Doutorado em Ciências Florestais) - Setor de Ciências Agrárias, Universidade Federal do Paraná, Curitiba, 2002.

PIETERSE, P. J.; BOUCHER, C. Is Burning a Standing Population of Invasive Legumes a Viable Control Method? Effects of a Wildfire on an Acacia mearnsii Population. Southern African Forestry Journal, Pretoria, n. 180, p. 15-21. nov. 1997.

PIÑA-RODRIGUES, F. C. M.; COSTA, L. G. S.; REIS, A. Estratégias de estabelecimento de espécies arbóreas e o manejo de florestas tropicais. In: CONGRESSO FLORESTAL BRASILEIRO, 6, 1990, Campos do Jordão. Anais... São Paulo: Sociedade Brasileira de Silvicultura, 1990. v. 1, p. 676-684.

RICHARDSON, D. M. Forestry trees as invasive alien. Conservation Biology, Boston, v. 12, n. 1, p. 18-26, feb. 1998.

RICHARDSON, D. M.; PYSEK, P.; REJMÁNEK, M.; BARBOUR, M. G.; PANETTA, F. D.; WEST, C. J. Naturalization and invasion of alien plants: concepts and definitions. Diversity and distribuitions, v. 6, p. 93-107. 2000.

RIO GRANDE SO SUL. Secretária da Agricultura e Abastecimento. Macrozoneamento agroecológico e econômico do Estado do Rio Grande do Sul. Porto Alegre, 1994.

SAS INSTITUTE INC. The SAS system for windows 8.02. Cary, 1999-2001. 1 CD-ROM. 
SHERY, S. P. The black wattle (Acacia mearnsii De Wild.). Pietermaritzburg: University of Natal Press, 1971.

STATISTICAL GRAPHICS CORP. Statgraphics Plus 5.1. 1994-2001. 1 CD-ROM.

STEEL, R. G. D.; TORRIE, J. H. Bioestadistica: principios y procedimientos. 2. ed. México: McGrawHill, 1988.

STEIN, P. P.; TONIETTO, L. Black Watle Silviculture in Brazil. In: BROWN, A. G.; KO, H. C. Black wattle and its utilisation. Barton: RIRDC, 1997. p. 78-82.

ZILLER, S. R. A. Estepe Gramíneo-Lenhosa no segundo planalto do Paraná: diagnóstico ambiental com enfoque à contaminação biológica. $268 \mathrm{f}$. Tese (Doutorado em Ciências Florestais) - Setor de Ciências Agrárias, Universidade Federal do Paraná, Curitiba, 2000.

ZILLER, S. R. Plantas exóticas invasoras: a ameaça da contaminação biológica. Ciência Hoje, São Paulo, n. 178, p. 77-79, 2001.

ZIMMERMANN, F. J. P. Estatística aplicada à pesquisa agrícola. Santo Antonio de Goiás: Embrapa Arroz e Feijão, 2004. 